\title{
Knowledge attitude and practice of malignancies among PLWHIV in Nigeria
}

\author{
Clement Adebamowo ${ }^{1,2^{*}}$, Elima Jedy-Agba', Emmanuel Oga', Susan Yilme', William Blattner ${ }^{1}$ \\ From 13th International Conference on Malignancies in AIDS and Other Acquired Immunodeficiencies \\ (ICMAOI) \\ Bethesda, MD, USA. 7-8 November 2011
}

\section{Background}

HIV+ individuals are at increased risk of cancers [1]. Data suggest active surveillance and screening are required otherwise cancers in this population will present in advanced stages [2]. Early diagnosis depends on increased awareness. Previous studies noted low levels of awareness of cancers in LMIC and there is need to provide contextual, culturally appropriate health education [3]. We elucidate knowledge, practice and attitude (KAP) of PLWHIV in Nigeria to provide foundation for client education.

\section{Material and methods}

Random sample of HIV+ and HIV- persons in Nigeria, were consented, and asked to participate in FGD on AIDS Associated Malignancies. Each FGD consisted of 10 persons, managed by a researcher and a note-taker using a discussion guide. FGD was recorded, transcribed and analyzed.

\section{Results}

Most participants had heard about cancer and considered it a fatal disease, but they had poor knowledge of the causes. None had heard of any of the common cancers that occur in PLWHIV. When asked about specific cancer like Kaposi Sarcoma, Lymphoma and Cervical Cancer, only cervical cancer was mentioned and while they know that it occurs in female reproductive tract, they did not associate it with HIV.

Most respondents did not believe that it is possible to have HIV and cancer though some opined that it may be possible since both are caused by viruses.
Most respondents think that cancer is incurable or treatable by traditional means only.

Participants emphasized use of mass media, community engagement, pre-test counseling and confidentiality as issues that need to be attended to in order to have successful screening program.

\section{Conclusions}

This study showed low levels of awareness of cancer among PLWHIV.

\section{Acknowledgement}

This study is supported by the IHV-UM Capacity Development for Research into AIDS Associated Malignancies (NIH/NCI D43CA153792-01 PI,

Adebamowo) and IHV-UM AIDS International Training and Research Program (NIH/FIC D43TW001041-11 PI, Blattner).

\section{Author details}

'Office of Strategic Information, Research and Training, Institute of Human Virology, Abuja, Nigeria. ${ }^{2}$ Department of Epidemiology, Institute of Human Virology, University of Maryland School of Medicine, Baltimore, MD, USA.

Published: 19 April 2012

\section{References}

1. Crum-Cianflone N, Hullsiek KH, Marconi V, Weintrob A, Ganesan A, Barthel RV, Fraser S, Agan BK, Wegner S: Trends in the incidence of cancers among HIV-infected persons and the impact of antiretroviral therapy: a 20-year cohort study. AIDS 2009, 23:41-50.

2. Heard I: Prevention of cervical cancer in women with HIV. Curr Opin HIV AIDS 2009, 4:68-73.

3. Ajayi IO, Adewole IF: Knowledge and attitude of general outpatient attendants in Nigeria to cervical cancer. Cent Afr J Med 1998, 44:41-43.

doi:10.1186/1750-9378-7-S1-P16

Cite this article as: Adebamowo et al:: Knowledge attitude and practice of malignancies among PLWHIV in Nigeria. Infectious Agents and Cancer 2012 7(Suppl 1):P16.

\footnotetext{
* Correspondence: cadebamo@yahoo.com

'Office of Strategic Information, Research and Training, Institute of Human Virology, Abuja, Nigeria

Full list of author information is available at the end of the article
} 